\title{
DANGDORA KOVI: SIKLUS KEHIDUPAN WANITA DAYAK SOPUNTAN DALAM KARYA TARI
}

\author{
Sisilia Hangin \\ Jurusan Tari Fakultas Seni Pertunjukan, \\ PSDKU Institut Seni Indonesia Yogyakarta Rintisan ISBI Kaltim \\ Email: sisiliahangin0211@gmail.com
}

\begin{abstract}
RINGKASAN
Karya berjudul "Dangdora Kovi" adalah video tari yang bersumber dari ritual upacara adat yang dilakukan wanita suku Dayak Soputan dalam siklus kehidupan yaitu lahir, tumbuh, dan dewasa. Tradisi dalam suku Dayak Soputan merupakan suatu kebiasaan yang dilakukan dalam setiap peristiwa ataupun proses kehidupan, yang mengandung nilai, makna, serta tujuan tertentu. Gerak tari berangkat dari pola tradisi dengan pengembangan motif gerak nyerilit, seliung, ngancet, dan kepupeq yang dirangkum kedalam tiga segmen. Pola iringan menggunakan instrumen Sapeq dan Gong, dan hutan dipilih sebagai tempat pementasan karya. Sinematografi adalah sebuah ilmu terapan yang membahas tentang penangkapan gambar dan sekaligus penggabungan gambar tersebut, sehingga menjadi rangkaian gambar yang memiliki kemampuan menyampaikan ide dan cerita, yang dilengkapi dengan konsep Ten Tools, menjadi teknik yang digunakan untuk menciptakan panggung baru dalam seni pertunjukan tari dengan penggunaan kamera untuk mengarahkan presepsi penonton terhadap visual yang dilihat.
\end{abstract}

Kata Kunci : Damgdora, Tari Tunggal, Video Tari

\section{ABSTRACT}

Tradition in the Dayak Soputan tribe is a custom carried out in every event or process of community life, that iscontains certain values, meanings, and goals. The dance work entitled "Dangdora Kovi "comes from the life process of Dayak Soputan women in their tradition, The stylists link the life processes of Dayak women in their tradition to customs dangdora, above becomes a sequence that is applied into the structure a single dance work entitled Dangdora Kovi, by applying management traditional ceremonial rituals, personal experiences, and ideas of dance stylists with forms movements which are summarized into dance videos.

The presentation of the work "Dangdora Kovi" departs from the traditional pattern withdevelopment of motive motion nyerilit, seliung, ngancet and kepupeq. This work presented the 
ceremonial procession, personal experiences, and ideas of the stylists which is summarized into three segments, namely birth, growth and adulthood. This workcarrying midi music (recording), using Sapeq and Gong as basic instruments of dance music. forest is the selected place as the backgroundstaging works.

Cinematography is an applied science that discusses capture images and at the same time combining these images, so that it becomes a series of images that have the ability to convey ideas and stories, equipped with the concept of Ten Tools, the technique used for creating a new stage in the performing arts of dance with use a camera to direct the audience's perception of the visuals they see.

Keywords: Dangdora, Single Dance, Dance Video

\section{PENDAHULUAN}

Karya tari berjudul "Dangdora Kovi" bersumber dari proses kehidupan wanita Dayak Soputan dalam tradisinya. Tradisi dalam suku Dayak Soputan merupakan suatu kebiasaan yang dilakukan dalam setiap peristiwa ataupun proses kehidupan masyarakat, yang mengandung nilai, makna, serta tujuan tertentu. Salah satu tradisi yang melekat erat adalah upacara adat yang dilakukan kepada wanita khususnya wanita Dayak Soputan, adalah upacara Besape, Moru Aneq, penaandaan Tato, dan Telinga Panjang. Upacara ini menjadikan wanita Dayak Soputan memiliki nilai tinggi di mata masyarakat. Pada mulanya kata "perempuan" mengacu pada salah satu jenis kelamin manusia, tetapi kemudian menjadi salah satu pembeda keberadaan: mulai dari kehidupan binatang, tumbuhan, kebudayaan, kosmologi, hingga mitologi. ${ }^{1}$

Yustinus Ibo Hului selaku ketua
Dewan Adat Dayak Mahakam Ulu mengatakan bahwa wanita suku Dayak Soputan kecamatan Long Apari memiliki keistimewaan, ciri khas, nilai dan makna, yang terkait di dalam Adet Dangdora (Adat Wanita). ${ }^{2}$ Adet Dangdora yang menjadi sumber penciptaan karya tari ini mencerminkan keistimewaan wanita Dayak Soputan yang ditandai dengan upacara adat yang dilakukan untuk mendoakan, memberkati dan melindungi kaum wanita suku Dayak, agar terhindar dari hal-hal buruk yang tidak diinginkan. Penaandaan ini dilakukan sejak

\footnotetext{
${ }^{1}$ Nikodemus Niko, Perempuan dayak Benawan, Yogyakarta : Deepublish, 2018. P. 8.

${ }^{2}$ Wawancara dengan Yustinus Ibo Hului selaku Ketua Dewan Adat Dayak kab, Mahakam Ulu, 2019 melalui Telefon.
} 
masih di dalam kandungan sampai pada saat tumbuh dewasa, menjadi tua, dan kembali dilakukan pada wanita mengandung sehingga membentuk lingkaran yang kembali ke titik awal, terus dilakukan berulang-ulang dalam proses kehidupan wanita dan disebut sebagai tradisi.

Karya ini dipentaskan dalam bentuk video tari. Pembuatan video tari Dangdora Kovi menggunakan struktur naratif yaitu suatu rangkaia peristiwa yang berhubungan satu sama lain yang terkait oleh logika sebab akibat (kausalita) yang terjadi dalam satu ruang dan waktu. Suatu kejadian tidak bisa terjadi begitu saja tanpa ada alasan yang jelas. ${ }^{3} \quad$ Proses upacara ini dimulai pada saat wanita mengandung dan diberi nama Adat Besape (adat hamil pertama), upacara ini dilakukan untuk ibu hamil agar membatasi dirinya terhadap perbuatan buruk, dan nafsu duniawi sehingga upacara dilakukan pada saat usia kandungan 7 bulan agar pantangan yang dilewati tidak terlalu lama, sehingga bayi yang dikandung dan ibu hamil tidak mengalami musibah seperti kepercayaan orang Dayak. ${ }^{4}$ Upacara ini mengandung mandat untuk janin yang sedang tumbuh dan berkembang agar ketika lahir menjadi manusia yang berbudi pekerti baik. Dalam upacara

\footnotetext{
${ }^{3}$ Himawan Pratista, Memahami Film. Jakarta : Montase Press. 2017. P. 63

${ }^{4}$ Wawancara dengan Yustinus Ibo Hului selaku Ketua Dewan Adat Dayak kab, Mahakam Ulu, 2019 melalui Telefon.
}

digunakan cohung (seraung) sebagai pelindung dan menjadi batas dari hal buruk bagi ibu hamil dan janin yang dikandung, urun potiq (kain putih) sebagai kostum yang digunakan untuk meutupi tubuh dan perut ibu hamil, dan kotip daya motum (taah hitam). Adapun barang-barang yang digunakan dalam upacara ini antara lain, urun potiq, inu buno, toun nyang arit tongang, cohung daya, kotip daya motum, klavi suvon daruq, sivong batik, olok eton, depa avit, samit kajang, uong siu, pari puut. Tata laksana ritual adat dilaksanakan dengan $4 \mathrm{x}$ turun naik ke sungai. ${ }^{5}$

Ketika bayi yang dikandung telah lahir maka diadakan upacara Moru Aneq yaitu upacara pembasuhan bayi yang dicuci dan dibersihkan dengan air mengalir kemudian diberi nama sebagai simbol keberkahan dalam hidupnya. ${ }^{6}$ Upacara ini dilakukan dengan membawa bayi ke sungai dan dimandikan diikuti dengan menyebut atau memanggil bayi dengan nama yang sudah diberikan, kemudian sang bayi menjalani pembasuhan sebanyak $2 \times 8$ putaran diiringi bunyi suara gong selama ritual adat berlangsung. Adapun barang-barang adat yang digunakan ialah Boning (gendongan bayi), dan Cohung Sulru (seraung). ${ }^{7}$ Beranjak

\footnotetext{
${ }^{5}$ Dewan Adat Dayak Mahakam Ulu, Kitab Hukum Adat Dayak Hahakam Ulu,Malang: Kota Tua malang, 2019 p.71.p.73

${ }^{6}$ Wawancara dengan Yustinus Ibo Hului selaku Ketua Dewan Adat Dayak kab, Mahakam Ulu, 2019 melalui Telefon.

${ }^{7}$ Dewan Adat Dayak Mahakam Ulu, Kitab Hukum Adat Dayak Hahakam Ulu, Malang: Kota Tua malang, 2019
} 
ke tahap pendewasaan wanita Dayak mendapatkan penandaan fisik berupa tato dan telinga panjang yang diberikan sebagai simbol kecantikan, pendewasaan, kekuatan, dan ciri khas sebagai penandaan identitas. Pemanjangan daun telinga dilakukan dengan menindik bagian daun telinga dan menambahkan satu buah anting atau subang perak. Gaya anting yang berbeda-beda menandakan perbedaan status jenis kelamin. ${ }^{8}$ Gaya-gaya tertentu menandakan bahwa seseorang adalah seorang yang jago dan gagah berani. Pemanjangan telinga secara tradisional menurut masyarakat Dayak berfungsi sebagai penanda identitas kemanusiaan. Penandaan fisik lainnya adalah tato yaitu prosesi melukis sekujur tubuh dengan tinta hitam yang dihasilkan dari asap damak yaitu bahan bakar lampu alam (Nyatong), yang diolah menjadi tinta tato dengan bahan dan alat tradisional. ${ }^{9}$

Proses kehidupan wanita Dayak dalam tradisinya pada Adat Dangdora, di atas menjadi satu rangkaian yang diwujudkan ke dalam karya tari tunggal berjudul

"Dangdora Kovi", dengan menerapkan tata laksana ritual adat ke dalam bentuk gerak. Dalam buku koreografi Bentuk-Teknik-Isi

\footnotetext{
${ }^{8}$ Yekti Maunati, Identits Dayak, Yogyakarta : LKiS Yogyakarta,2004, p.48.p49

${ }^{9}$ Wawancara dengan Batoq Laga petinggi dan tokoh budayawan Long Penaeh 1 Kecamatan Long Apari 2019 ${ }^{10}$ Y. Sumandiyo Hadi, Koreografi-Bentuk-Tekni-Isi Yogyakarta: Cipta Media,2016, p.10.
}

\author{
yang ditulis oleh Y. Sumaniyo Hadi
}

menyatakan bahwa:

Gerak adalah dasar ekspresi oleh sebab itu gerak kita pahami sebagai ekspresi dari semua pengalaman emosional, dalam koreografi atau tari pengalaman mental dan emosional diekspresikan lewat medium yang tidak rasional, atau tidak berdasarkan pada pikiran, tetapi pada perasaan, sikap, imaji, yakni gerakan tubuh. ${ }^{10}$

Unsur pokok seni adalah segala potensi gerak yang ada pada tubuh manusia, sejak manusia lahir potensi seni yang ada pada tubuh manusia adalah gerak dan suara. ${ }^{10}$ Menciptakan sebuah karya dengan alur cerita yang dimulai dari seorang wanita mengandung, kemudian melahirkan, tumbuh dan memasuki proses pendewasaan yang diiringi dengan prosesi upacara adat sebagai bentuk perlindungan atau mendoakan dan menjauhkan seorang wanita dari hal buruk. Dalam menciptakan alur karya ini penata menggunakan pendekatan empiris yaitu berdasarkan pengalaman, pengetahuan, dan pengamatan penata. Penata mencoba menghubungkan ke dalam diri penata sendiri sebagai wanita keturunan Dayak yang mendapat keistimewaan menjadi bagian dalam upacara, dengan mendalami nilai, simbol, makna dan keistimewaan yang terkandung di dalam "Adat Dangdora". Prosesi dalam

\footnotetext{
${ }^{10}$ Sumaryono, Antropologi Tari Dakam Prespektif Indonesia. Yogyakarta : Media Kreatifa, 2011. P. 5
} 
upacara menjadi landasan dalam menciptakan gerak yang dihubungkan dengan ketubuhan penari, pengalam dan gagasan penata tari. Karya ini dibuat dalam bentuk Video Tari dengan mempresentasikan isi dari prosesi upacara yang dirangkum kedalam 3 urutan segmen, yaitu Lahir, Tumbuh, dan Dewasa. Bentuk perwujudan dan proses yang ada dalam upacara membuat pengkarya tertarik untuk menciptakan koreografi tunggal satu penari, dengan menghubungkan proses kehidupan wanita Dayak Soputan dalam tradisinya dengan diri penata tari. Pemaknaan nilai dan simbol dalam setiap upacara menjadi motivasi dan rangsang dalam karya yang dibuat.

Karya tari ini akan ditampilkan dalam bentuk video tari dengan mengutamakan Sinematografi sebuah ilmu terapan yang membahas tentang penangkapan gambar dan sekaligus penggabungan gambar tersebut sehingga menjadi rangkaian gambar yang memiliki kemampuan menyampaikan ide dan cerita. $^{11}$ Dengan menggunakan konsep Ten Tools sebagai besik pembuatan video yang terdiri dari: Shot size and lenses, camera height ad angel, camera motion, focal depth of field, light and dark, lines and linear

\footnotetext{
${ }^{11}$ Himawan Pratista, Memahami Film. Jakarta : Montase Press. 2017. P.
}

perspective, layer, weight, color, and texture. ${ }^{12}$ Menjadi teknik yang digunakan untuk menciptakan panggung baru dalam seni pertunjukan tari dengan penggunaan kamera untuk mengarahkan presepsi penonton terhadap visual yang dilihat.

\section{PEMBAHASAN}

Karya "Dangdora Kovi" merupakan karya tari yang merepresentasikan proses kehidupan wanita Dayak Soputan dalam tradisinya, yang dibagi ke dalam 3 segmen yaitu Lahir, Tumbuh, dan Dewasa yang diwujudkan ke dalam bentuk Video Tari. Di dalam setiap segmen terdapat beberapa adegan yang dipilah untuk menyampaikan tahap per tahap peroses tumbuhnya seorang wanita dibalut dalam prosesi upacara adat yang memiliki keistimewaan, ciri khas, nilai, dan makna. Beberapa aspek tari yang dapat membantu untuk menyampaikan pesan dari sebuah karya tari yaitu: 1). jumlah satu penari wanita sebagai penggambaran diri penata tari dalam melakukan upacara adat dangdora; 2). motif gerak yang berpijak pada gerak tari tunggal Dayak Soputan yaitu nelasut, kepupeq, ngancet, seliung. 3). properti Boning (gendongan bayi), Cohung (seraung), dan Kain Merah, digunakan dalam koreografi ini

\footnotetext{
12 Kurl Lancastr Basic Chinematography London, new york : Routledge 2019. P. 53. P. 54
} 
untuk menyampaikan makna yang terkandung di dalam proses kehidupan wanita Dayak Soputan dalam tradisinya. 4). Musik iringan yang digunakan adalah musik Sapeq yang dipadukan dengan instrumen Gong dan penambahan intrumen lain sebagai pendukung 5). Busana yang digunakan terdiri dari beberapa macam sesuai dengan adegan yang terdapat dalam prosesi upacara di antaranya kain putih dalam adegan mengandung, kain merah dalam adegan melahirkan, baju kulit kayu dan kostum putih dalam dalam adegan tumbuh, kostum hitam dalam adegan tangguh. 6). Pemilihan hutan sebagai tempat pengambilan video untuk mendapatkan kesan alami dan melekat pada kehidupan suku Dayak. Karya ini dipentaskan dalam bentuk Video Tari yang mengutamakan sinematografi sebagai aspek dalam pembuatan video tari. Karya Dangdora Kovi berdurasi 15 menit yang dibagi menjadi 3 segmen dengan pembagian 5 menit per segmen. Adapun uraian karya sebagai berikut:

\section{A. Struktur Karya}

\section{Segmen 1. (Lahir)}

a. Adegan Pertama Nyerilit ( Upacara 7 Bulanan)

Introduksi pada karya ini memperlihatkan air mengalir dan hutan sebagai latar, dengan teknik editing
Establishing Shot yaitu Shot yang memperlihatkan latar secara luas, sebagian, hingga keseluruhan ruang bersama isinya, dengan menggunakan sudut straight-on angle sebagai sudut pengambilan gambar dan shot close up untuk menunjukkan detail tempat dilaksanakannya pertunjukan karya Dangdora Kovi. Air menjadi simbol pembersihan atau penyucian diri yang digunakan dalam setiap prosesi upacara dan hutan menjadi simbol rumah atau tempat menetap suku Dayak dari zaman dulu sampai saat ini. Kedua elemen itu digunakan untuk menunjukkan kehidupan suku Dayak yang hidup berdampingan dengan alam dan upacara tradisi dalam kehidupan sehari-hari.

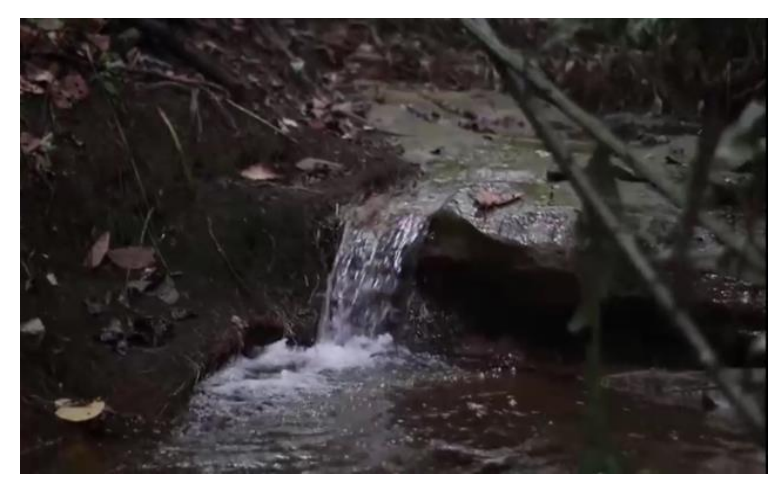

Gambar 1. Introduksi menunjukkan latar hutan dan air. (Foto: Fariz, 2020)

Pada adegan pertama memperlihatkan cohung (seraung) sebagai simbol perlindungan yang digunakan dalam upacara nyerilit memiliki makna melindungi ibu hamil dan janin yang dikandung dari hal buruk yang tidak diinginkan. Pada adegan pertama ini pengambilan gambar menggunakan jarak close 
up dengan tujuan memberikan penekanan terhadap informasi yang ingin disampaikan.

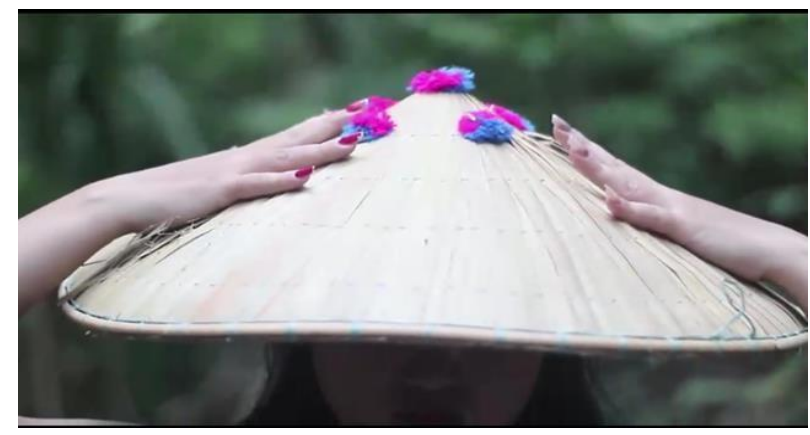

Gambar 2. Adegan 1 menunjukkan properti yang digunakan

(Foto: Fariz, 2020)

Adegan pertama inframe ini menampilkan seorang wanita yang sedang mengandung (hamil pertama), menggunakan kain putih lambang (kesucian, bersih) dan cohung (pembatas, pelindung). Adegan pertama ini diawali dengan mengusapkan tangan dari atas kepala, tubuh dan sampai pada perut, dengan tujuan menyapu segala hal buruk bagi ibu dan calon bayi sebelum upacara dimulai

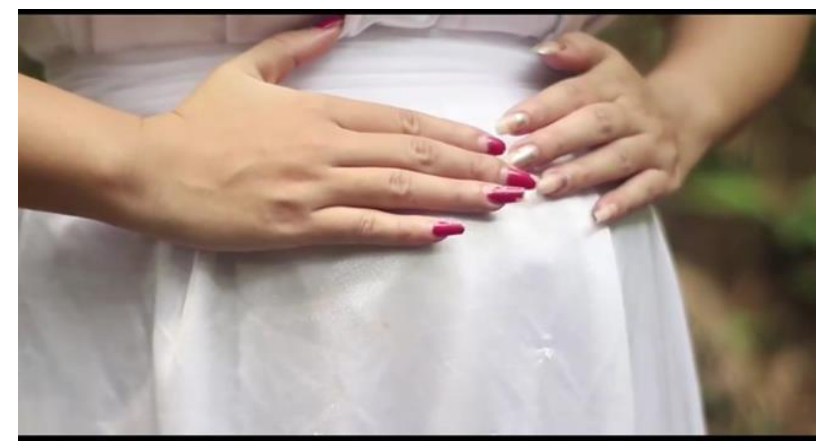

Gambar 3. Adegan menunjukkan bagian perut dengan teknik Close up (Foto: Fariz,2020)
Penari membuat buat pola lingkaran yang diadaptasi dari pola lingkaran dalam prosesi upacara yang asli pada upacara Nyerilit. Pola lingkaran ini menunjukkan proses kehidupan seorang wanita yang melakukan upacara dari dalam kandungan, tumbuh dewasa, menikah, kemudian kembali mengandung yang menciptakan pola lingkaran dengan kembali ke titik awal lagi. Penari bergerak kemudian menuju air untuk melakukan proses pembasuhan, memasukkan seluruh badan ke dalam air kemudian melepaskan seraung dan mencelupkan seraung ke dalam air sebagai tanda pembersihan seluruh anggota tubuh dan janin yang dikandung. Menuju proses melahirkan, penari bergerak dengan beberapa kali memegang perut yang mulai merasakan kesakitan dengan ekspresi kesakitan dan membuka kaki sebagai simbol masuk ke proses kelahiran.

\section{b. Adegan Dua (Rahim)}

Adegan ini mempresentasikan proses melahirkan dan proses kelahiran seorang wanita dari dalam rahim. Pada awal adegan penata menghadirkan cairan merah mengalir dari atas yang menyimbolkan adegan masuk pada bagian rahim. Seorang penari di atas batu terbalut kain merah yang penuh dengan lumuran darah sebagai simbol berada di dalam Rahim. Dengan posisi menekuk badan 
dan kaki (mengecil) gerakan pertama yang dilakukan adalah bergerak kecil sesekali shaking, kemudian gerak membesar. Setelah bergerak membesar perlahan muncul kepala disusul oleh tangan, lalu muncul kain merah terbentang dari arah penari ke bawah yang menandakan bayi telah lahir.

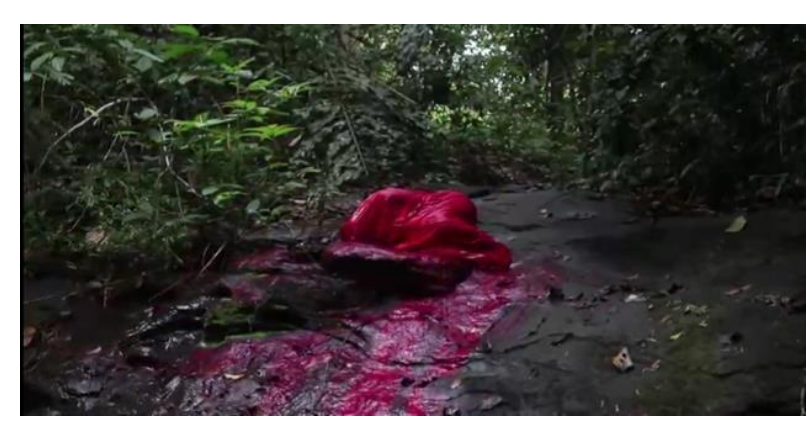

Gambar 4. Adegan menunjukkan Rahin (Foto : Fariz, 2020)

\section{Segmen 2 (Tumbuh)}

a. Adegan pertama Moru Aneq ( Upacara Pembasuhan Anak)

Adegan ini dimulai dengan munculnya Boning (gendongan bayi) inframe sebagai simbol tumbuh. Properti boning ini digunakan untuk menggendong bayi sampai tumbuh menjadi balita. Dari dalam boning muncul tangan penari perlahan, sampai pada saat ke luar kepala dan muncullah seorang wanita dengan seluruh badan sampai bagian pinggang bergerak kemudian kembali ke dalam boning.

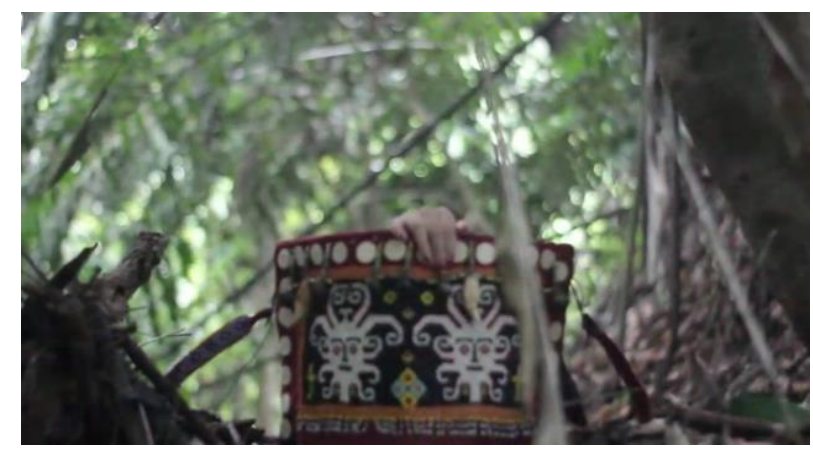

Gambar 5. Simbol pada adegan tumbuh (Foto : Fariz, 2020)

Pada adegan ini memperlihatkan seorang penari menghadap ke belakang dan menggunakan properti lengkap dengan boning yang digendong dan cohung di atas kepala. Penari kemudian bergerak berbalik arah kemudian membuat pola lingkaran denga

bergerak membuat pola lingkaran menghadap ke segala arah pola lingkaran yang diadaptasi dari pola lingkaran dalam prosesi upacara yang asli pada upacara Moru Anaq. Sama seperti adegan pertama pada segmen satu, pola lingkaran ini menunjukkan proses kehidupan seorang wanita yang melakukan upacara dari dalam kandungan, tumbuh dewasa, menikah,

kemudian kembali mengandung yang menciptakan pola lingkaran dengan kembali ke titik awal lagi. Setelah membuat lingaran penari melepaskan boning yang digendong dan menuju sungai. Penari masuk ke dalam air, kemudian melakukan pembasuhan dengan 
memercikan air ke arah boning lalu kembali membuat pola lingkaran dengan berputar.

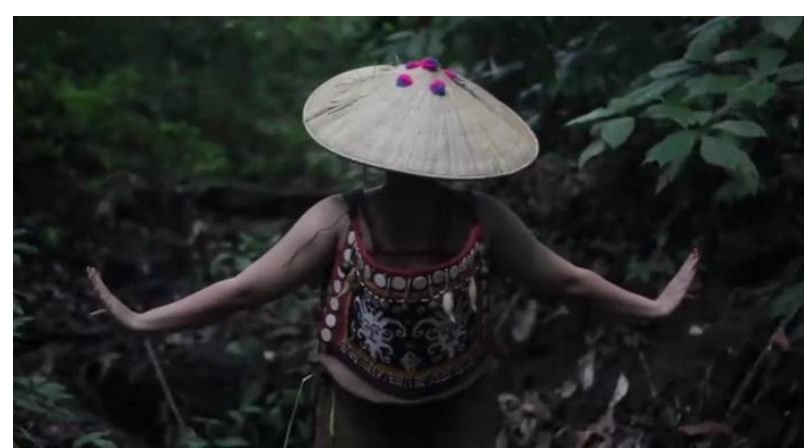

Gambar 6. Penggunaan seluruh properti menuju upacara moru aneq (Foto: Fariz, 2020)

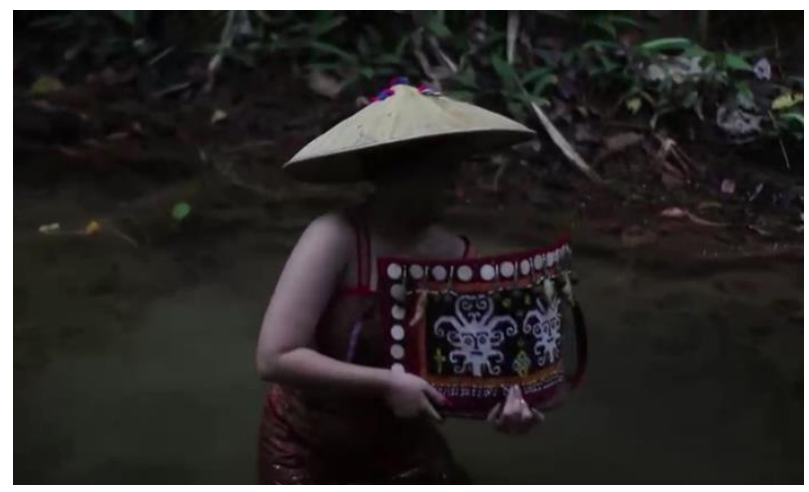

Gambar 7: Adegan Prosesi moru aneq (Foto: Fariz, 2020)

\section{b. Adegan Dua (Bengonam)}

Adegan ini mempresentasikan seorang wanita yang telah tumbuh dewasa dan bermain di sungai dan di hutan. Segmen ini diadaptasi dari kebiasaan penata tari pada masa lalu sewaktu kecil, dalam proses tumbuh penata tari selalu bermain di hutan dan mandi di sungai hal ini menginspirasi penata untuk memasukkan adegan ini dalam karya "Dangdora Kovi" Dimulai dengan muncul penari dari dalam air dengan baju putih polos.

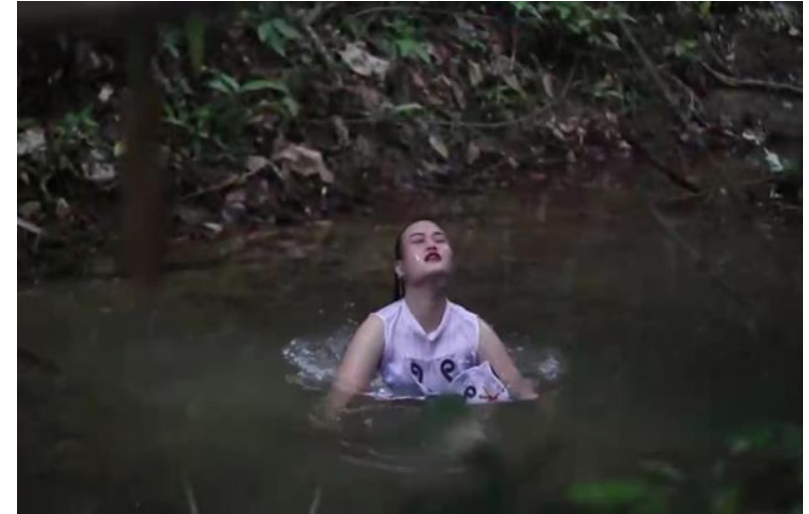

Gambar 8: Adegan seorang wanita muncul dari dalam air

(Foto: Fariz, 2020)

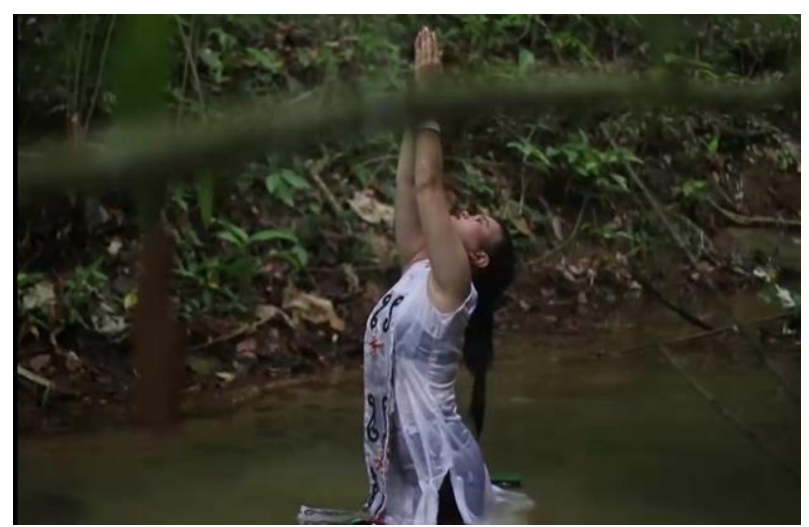

Gambar 9: Gerakan menengadah ke atas simbol tumbuh dalam visual gerak

(Foto: Fariz, 2020)

\section{Segmen 3 ( Dewasa)}

Adegan Simbol Tato dan Telinga Panjang Adegan ini dimulai dengan close up bagian tangan yang memberikan penekanan informasi terhadap detail tangan, memiliki tato dan telinga panjang sebagai simbol pendewasaan. Segmen ini mempresentasikan wanita yang telah tumbuh dewasa dengan menjadi seorang gadis yang tangguh dengan karakter lemah lembut namun tetap kuat. Hal ini ditunjukkan dengan gerakan yang bersifat 


\section{JOGED}

tegas dan juga lembut yang diaplikasikan dengan ketubuhan penari
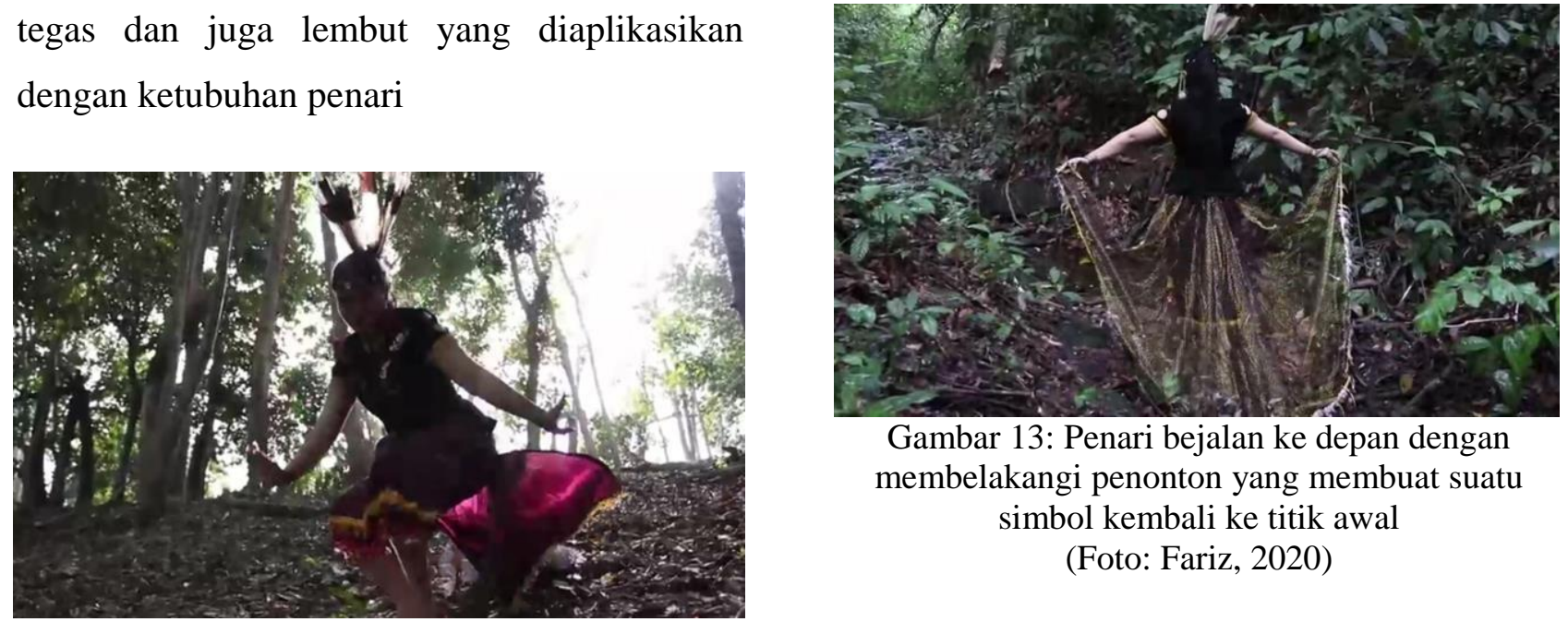

Gambar 13: Penari bejalan ke depan dengan membelakangi penonton yang membuat suatu simbol kembali ke titik awal (Foto: Fariz, 2020)

Gambar 10: Pembukaan Adegan dewasa

(Foto : Fariz, 2020)

\section{B. Konsep Garap Tari}

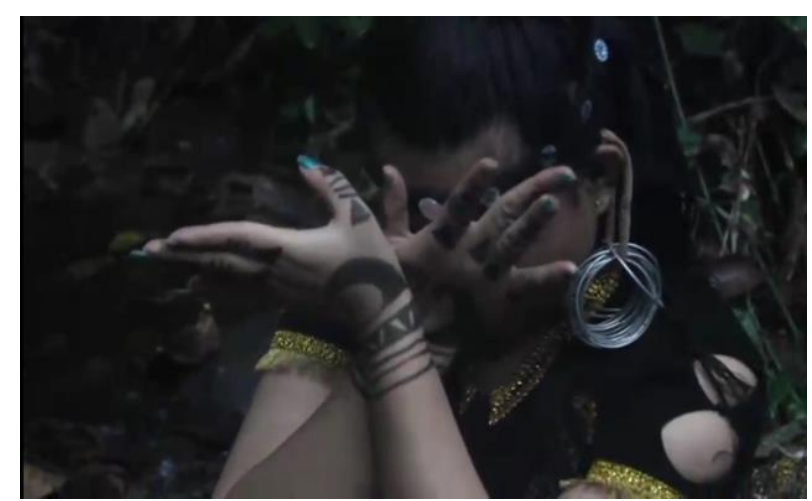

1. Gerak

Gerak yang dihasilkan merupakan proses dari eksplorasi terhadap rangsang visual dan juga gagasan terhadap proses kehidupan wanita Dayak Soputan dalam tradisinya. Proses pencarian gerak didasari oleh ketubuhan penata tari dengan menggunakan unsur motivasi dalam setiap gerak. Doris Humphrey dalam bukunya berjudul Seni Menata Tari, menjelaskan bahwa:

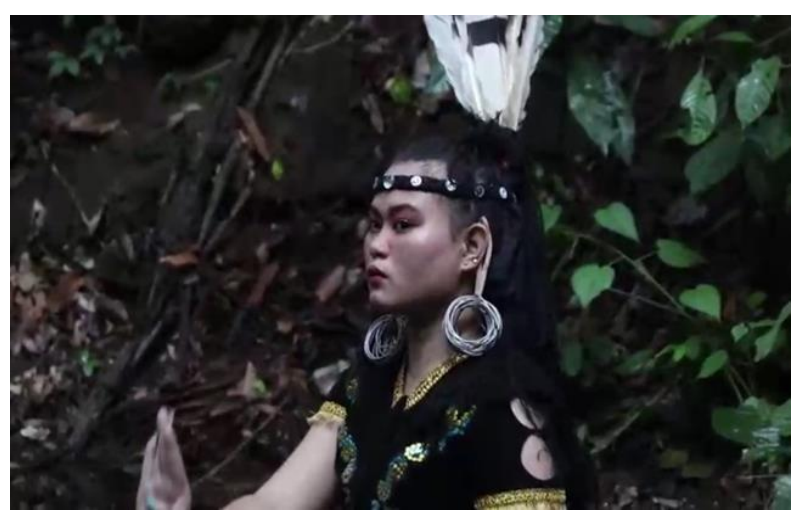

Gambar 12: Pemunculan karakter melalui ekspresi (Foto : Fariz, 2020)

Setiap gerakan yang dibuat, baik oleh manusia maupun dalam dunia binatang, memiliki desain keruangan dan berhubungan dengan benda-benda lain dalam dimensi ruang dan waktu; aliran kekuatan yang disebut "dinamika" dan "irama" atau "ritme". Gerak dilahirkan karena adanya sejumlah alasan atau sebab tertentu: ada yang disengaja ada pula yang tidak, karena alasan jasmaniah, batiniah, emosional, atau 
karena insting yang semuanya biasa dikenal atau disebut "motivasi" gerak. ${ }^{13}$

Penjelasan Doris Humphrey di atas menjadi landasan penata menciptakan alur karya dimulai dari Lahir, Tumbuh, dan Dewasa yang masing-masing gerak memiliki motivasi untuk disampaikan. Gerak tari yang digunakan dalam karya ini tetap mengacu pada gerak tradisi suku Dayak Soputan, dengan gerak dasar Tari Kenya yang mengandung motif gerak Nyeliung, Kepupeq, Nelasut dan Ngancet. Pemilihan gerak dalam karya tari ini hasil dari eksplorasi terhadap tema yang dibangun. Penata mengolah kemudian mengembangkan kembali sesuai dengan keinginan atau kecenderungan inventif (mencipta/merancang), tentunya dibekali dengan pengalaman ketubuhan penata, sehingga pengembangan gerak yang dicipta dengan aspek ruang dan waktu tidak terlepas dari esensi awal penciptaan. Gerak dalam karya ini adalah gerak yang diadaptasi dari porosesi upacara yaitu Adet Nyerilit (Upacara Adat mengandung),

Adet Nganeq (Upacara Adat Melahirkan), Adet Besa'a (Upacara Adat Menikah), yang berpijak pada motif gerak tari Kenya Dayak Soputan.

\section{Penari}

\footnotetext{
${ }^{13}$ Doris Humphrey. Seni Menata Tari. Jakarta : Dewan Kesenian Jakarta 1983. P. 51
}

Dangdora Kovi ditarikan oleh satu orang penari wanita yaitu penata tari sendiri. Pemilihan penari wanita berjumlah satu orang didasari oleh garapan tari yang berbentuk tunggal, penggambaran diri penata sendiri sebagai wanita Dayak menjadi lebih mudah disampaikan dengan menari tunggal. Pemilihan penari tunggal juga dilandaskan dari setiap upacara yang dilakukan hanya untuk satu wanita dalam keadaan tertentu.

\section{Musik Tari}

Musik merupakan salah satu elemen yang berperan penting dalam karya Dangdora Kovi ini. Musik dapat menjadi jiwa (ruh) sebuah karya tari. Musik dan tari adalah bagian yang saling melengkapi satu sama lain. Suku Dayak umumnya juga memiliki banyak musik ensambel yang bersifat ritual yang hanya digunakan pada saat upacara dan tempat tertentu. ${ }^{14}$ Dalam buku Estetika Musik, yang ditulis oleh Suka Hardjana mengatakan bahwa: Sebagai ilmu teoritis ia akan sangat berguna dan sangat membantu menerangkan pengalaman-pengalaman batin seseorang dalam hubungannya dengan keindahankeindahan yang terkandung dalam hakikat musik. Secara praktis ia akan banyak

\footnotetext{
${ }^{14}$ Haryono Musik Suku Dayak. Sebuah catatan pelajaran di pedalaman kalimantan Yogyakarata: Institut Seni Indonesia. 2015. P. 159
} 
menunjang kegiatan-kegiatan artistik seharihari. ${ }^{15}$

\section{Penyajian musik yang mengusung konsep MIDI menjadi pilihan untuk mengiringi karya ini. Dengan mengusung konsep MIDI, penata berpijak pada Sapeq dan Gong sebagai instrumen dasar yang diadaptasi dari prosesi upacara Adat Dangdora yang dilakukan kepada wanita suku Dayak} Soputan. Alat musik sapeq merupakan alat musik petik yang terkenal pada masyarakat suku Dayak, instrumen ini termasuk ke dalam jenis instrumen chordophone yang berbentuk seperti dayung. ${ }^{16}$ Dalam upacara ini terdapat lirik/mantra yang mengandung petuah (nasihat) kepada yang menjalankan upacara, di antaranya adalah:

\section{Part I (Nyerilit)}

Aung Dengdora

Aung Dengdora

Aung Dengdora na murip be puru tanaq

Hikot ano hoang urip aung tiri do akan kejagaq

Adata Dangdora

Aung Dangdora

Adat Dangdora

\footnotetext{
${ }^{15}$ Suka Hardjana, Estetika Musik. Jakarta : Departemen Pendidikan dan Kebudayaan Direktorat jendral pendidikan dasar dan menengah 1983. P. 2

${ }^{16}$ Haryono Musik Suku Dayak. Sebuah catatan pelajaran di pedalaman kalimantan Yogyakarata : Institut Seni Indonesia. 2015. P. 133. P.135
}

\section{Part II (Rahim)}

\section{Nyaki kesingom urip cian}

\section{Balri arino na cian}

Na tu'u cohing lain

\section{Na tu'u cian adet}

Na tu'u pekecian aran.

4. Rias dan Busana

Rias wajah yang digunakan dalam karya ini adalah rias korektif yang menyesuaikan tema garapan. Rias dan busana dalam karya Dangdora Kovi memiliki beberapa pembagian khususnya pada bagian busana. Dalam menampilkan setiap adegan penata tari menggunakan kostum yang berbeda-beda, sesuai dengan adegan. Beberapa macam ostum yang digunakan yaitu, berbahan dasar kulit kayu yang merupakan baju asli suku Dayak pada jaman dulu, kain putih sebagai kostum adegan mengandung, kain merah sebagai kostum adegan melahirkan, baju manik, bulu enggang dan asesoris Dayak ada pada adegan wanita tangguh yang berarti wanita telah dewasa, simbol wanita Dayak Soputan. Untuk menyimbolkan kecantikan dan keanggunan pemilihan rambut panjang dengan cemara menjadi pilihan, ditambah dengan tato pada kedua tangan dan kedua kaki yang memiliki makna bagi suku Dayak Soputan yaitu motif nyatong singa (penerangan jalan menuju yang Maha Kuasa), dan telinga 
panjang yang bermaknakan selendang badan, penandaan akan kecantikan, keberanian, dan juga derajat. Penggunaan kirap sebagai ciri khas tradisi suku Dayak Soputan. Desain kostum adalah bentuk kreasi dari pemikira penata dalam menambah kesan kuat dan anggun yang ingin ditampilkan dengan tetap berpijak pada busana tradisi Dayak Soputan.

\section{Tempat Pertunjukan}

Dalam setiap kegiatan apapun selalu memerlukan tempat. Seni pertunjukan sangat memerlukan tempat khusus untuk menampung gagasan-gagasan kreatif untuk ditransformasikan. Karya ini tidak menggunakan panggung pertunjukan berbentuk prosenium seperti pada umumnya namun lebih kepada non komvensional artinya tidak di panggung, namun lebih kepada alam terbuka atau outdoor, tidak menggunakan lampu khusus namun memanfaatkan cahaya alami. Hutan menjadi tempat yang dipilih penari untuk menjadi area pementasan, guna mendapatkan kesan alami dari pesan yang ingin disampaikan, pemilihan hutan adalah tempat yang melekat pada kehidupan suku Dayak Soputan seperti yang dituliskn oleh Tjilik Riwut dan dikutip oleh Nikodemus Niko dalam bukunya yang berjudul Perempuan Dayak Benawan kedudukan pada Struktur Domisili dan Politik.
"Perempuan dayak seperti yang digambarkan oleh Riwut (2011:21) dalam bukunya yang berjudul Bawin Dayak (wanita Dayak), adalah orang yang hidup bebas di hutan rimba, berburu di sepanjang aliran sungai, kehidupan yang tidak terpisah dari alam. ${ }^{17}$ Selain dari pernyataan Tjilik Riwut, pemilihan hutan didasari oleh tempat pelaksanaan dari upacara yang dilakukan suku Dayak Soputan, di tempat terbuka dan menggunakan alam (sungai Mahakam) sebagai sarana untuk melakukan prosesi.

\section{Konsep Koreografi Filmis}

Konsep koreografi filmis menjadi pilihan yang digunakan dalam pembuatan karya Dangdora Kovi. Koreografi diambil berdasarkan hubungannya dengan sinema, atau jika merujuk pada istilah sinema sebagai gerak. Karya Dangdora Kovi ditampilkan dalam betuk video tari yang mengusung konsep Ten Tools yang dilengkapi dengan teknik sinematograf yaitu ilmu terapan yang membahas tentang penangkapan gambar dan sekaligus penggabungan gambar tersebut sehingga menjadi rangkaian gambar yang memiliki kemampuan menyampaikan ide dan cerita.. Sinematografi dalam karya ini sendiri menggunakan tiga aspek yakni:

\footnotetext{
${ }^{17}$ Nikodemus Niko, Perempuan Dayak Benawan, Yogyakarta : Deepublish, 2018. P. 3.
} 
1. Kamera dan film mencankup teknikteknik yang dapat dilakukan melalui kamera dan stok (data mentah) filmnya, seperti penggunaan lensa, kecepatan gerak gambar, efek visual, pewarnaan dan sebagainya.

2. Framing adalah hubungan kamera dengan obyek yang akan diambil seperti lingkup wilayah gambar atau frame, jarak, ketinggian, serta pergerakan kamera.

3. Sementara durasi gambar mencangkup lama atau durasi sebuah obyek yang diambil gambarnya oleh kamera.

Ketiga aspek ini dilengkapi dengan konsep video tari yang digunakan yaitu konsep Ten Tools yang terdiri dari: ${ }^{18}$

\section{Shot Size and Lenses,}

Ukuran bidikan menentukan apa yang dilihat audiens di antara komposisi, baik lebar, sedang, atau dekat (dalam kombinasi dalam penepatan kamera), dan ukuran ini menentukan tingkat keintiman dalam bidikan. Pada saat yang sama, panjang fokus lensa membentuk cara kita memandang bidikan ukuran, memperkuat psikologi sebuah adegan. Bagian ini membahas lebih dalam dampak psikologi lensa.

\section{Camera Height and Angel}

Penempatan kamera rendah, datar, atau tinggi mempengaruhi cara kita memandang subjek dan objek dari psikologis/ kekuatan sudut pandang. Penempatan kamera juga menentukan ukuran bidikan.

\section{Camera Motion}

\footnotetext{
${ }^{18}$ Kurl Lancas. Basic Chinematography. London, New york: Routledge 2019. pp. 53-54
}

Saat mengubah komposisi dalam bidikan, saat tidak statis (dikunci), bidikan mungkin dipegang dengan tangan, goyang, lambat, atau bergerak cepat, tetapi semua kasus itu harus memperkuat cerita, dan perubahan gerakan dalam sebuah adegan harus berputar di sekitar perubahan emosional dalam cerita, yang disebut kamera termotivasi gerakan.

\section{Focal Depth of Filed}

Fokus dalam atau kedalaman bidang dangkal yang mengutamakan kedalaman fokus pada setiap objek yang diambil

\section{Light and Dark}

Penempatan cahaya dan bayangan dalam setiap pengambilan gambar pada video tari yang dipertimbangkan dengan matang.

\section{Lines and Linear Perpective}

Penempatan garis yang terlihat di layar menunjukkan kedalaman- kedalaman atau kerataan gambar, serta energi horizontal, vertikal dan diagonal.

\section{Layer}

Penempatan objek latar depan, tengah, dan latar belakang dan subjek.

\section{Weight}

Ukuran atau berat visual atau objek dan subjek yang ditempatkan dikomposisi, baik menyeimbangkan atau tidak menyeimbangkannya dalam bingkai

\section{Color}

Warna dalam bidikan, dari pencahayaan hingga kostum, set, dan properti

\section{Texture}


Betapa halus atau kasarnya pemandangan secara fisik, dari permukaan tekstur furnitur, lantai, dan dinding hingga kostum, alat peraga, dan bahkan kulit dari pemain. Penempatan cahaya dan bayangan yang dihasilkan membentuk tekstur seperti penggunaan kabut atau asap untuk tekstur atmosfer, yang juga menentukan kelembutan atau ketajaman relatif dari sebuah gambar.

\section{PENUTUP}

"Dangdora Kovi" merupakan karya tari dalam bentuk video tari yang bersumber dari proses kehidupan wanita Dayak Soputan dalam tradisinya. Merepresentasikan proses kehidupan seorang wanita dari mengandung, lahir, tumbuh, dan menjadi wanita dewasa diiringi dengan prosesi upacara adat dalam setiap peristiwa yang dialaminya yaitu upacara nyerilit, moru aneq, dan penaandaan tato, telinga panjang. Upacara ini menjadikan wanita Dayak Soputan memiliki nilai tinggi di mata masyarakat.

Gerak yang digunakan diadaptasi dari motif gerak tari Kenya suku Dayak Soputan dengan menggunakan motif gerak kepupeq, seliung, Nelasut, dan ngancet. Diiringi instrumen Sapeq dan Gong yang dikemas ke dalam bentuk MIDI dan telah dikreasikan sesuai kebutuhan karya. Kostum yang digunakan juga diadaptasi dari kostum suku Dayak kemudian di kreasikan sesuai dengan tema dan adegan dalam alur cerita dalam karya. Karya ini dibuat dalam bentuk Video Tari dengan mempresentasikan isi dari prosesi upacara yang dirangkum ke dalam 3 urutan segmen, yaitu Lahir, Tumbuh, dan Dewasa.

\section{DAFTAR SUMBER ACUAN}

Bahari, Nooryan. 2008. Kritik Seni: Wacana, Apresiasi dan Kreasi. Yogyakarta : Pustaka Pelajar.

Dewan Adat dayak Mahakam Ulu, 2019. Kitab Hukum Adat Dayak Mahakam Ulu. Malang : Kota Tua

Danesi, Marcel. 2010. Pesan, Tanda, dan Makna: Buku Teks Dasar Mengenai Semiotika dan Teori Komunikasi. Yogyakarta : Jalasutra.

Hawkinns, M Alma. Terjemahan I Wayan Dibia. 2003. Bergerak Menurut Kata Hati.

Jakarta : Masyarakat Seni Pertunjukan Indonesia

Hadi, Y Sumandiyo, 2016. Koreografi Bentuk-Teknik-Isi. Yogyakarta : Cipta Media

Humphrey, Doris. 1983. Seni Menata Tari. Jakarta : Dewan Kesenian Jakarta

Hardajana, Suka. 1983 Estetika Musik, Jakarta Departemen Pendidikan dan kebudayaan 
Direktorat jendral pendidikan dasar dan Menengah

Koentjaraningrat. 1970. Manusia dan Kebudayaan Indonesia. Djakarta: Djambatan.

Kaplan, David dan Albert A. Manners. 1999. Teori Budaya. Yogyakarta: Pustaka Pelajar.

Langer, K. Suzan. 2006. Problematika Seni. Bandung : SUNAN AMBU PRESS

Lancester, Kurl. 2019. Basic Cinematograph. New York : Routlege

McPherson, Katrina. 2006. Making Video Dance: A Step-by-Step Guide to Creating Dance for the Screen 1st edition. London and New York : Routledge.

Maunnanti, Yekti. 2004. Identitas Dayak. Yogyakarta : LKis Yogyakarta

Martono, Hendro. 2015. Mengenal Tata Cahaya Seni Pertunjukan. Yogyakarta : Cipta Media.

Meri, La. 1986. penerjemah Soedarsono. Elem-Elem Dasar Komposisi Tari. Yogyakarta : lagalogo

Nuraini, Indah. 2016. Metode Belajar Tari Puteri Gaya Surakarta. Yogyakarta: Badan Penerbit ISI Yogyakarta.

Nuraini, Indah. 2011. Tata Rias dan Busana: Wayang Orang Gaya Surakarta. Yogyakarta : Badan Penerbit ISI Yogyakarta.
Niko, Nikodmusniko. 2018. Perempuan Dayak Benawan. Yogyakarta : Deepublish.

Pratista, Himawa. 2017. Memahami Film. Jakarta : Montase Press

Piliang, Yasraf Amir. 2008. Narasi Simbolik Seni $\begin{array}{r}\text { Rupa } \\ \text { Kontemporer }\end{array}$
Yndonesia.
Yogyakarta : ISACBOOK

Ricoeur, Paul. 2012. Teori Interprestasi Memahami Teks, Penafsiran, dan Metodologi. Jogjakarta : IRCiSoD

Sumaryono, 2011. Antropologi Tari Dalam Prespektif Indonesia Yogyakarta : Media kreatif

Sugiharto, Bambang. 2013. Untuk Apa Seni. Bandung : Matahari

Smith, Jacqueline.1976. Dance Composition: A Practical Guide For Teachers. London: Lepus Book, terj.Ben Suharto, S.S.T.1985. Komposisi Tari Sebuah Petunjuk Praktis Bagi Guru. Yogyakarta: Ikalasti

Soedarsono, R. M. 2002. Seni Pertunjukan Indonesia di Era Globalisasi. Yogyakarta. Gadjah Mada University Press. 